This is an electronic reprint of the original article. This reprint may differ from the original in pagination and typographic detail.

Author(s): Hämäläinen, Raija; Vähäsantanen, Katja

Title: $\quad$ Theoretical and pedagogical perspectives on orchestrating creativity and collaborative learning

Year: $\quad 2011$

Version:

Please cite the original version:

Hämäläinen, R., \& Vähäsantanen, K. (2011). Theoretical and pedagogical perspectives on orchestrating creativity and collaborative learning. Educational Research Review, 6(3), 169-184. https://doi.org/10.1016/j.edurev.2011.08.001

All material supplied via JYX is protected by copyright and other intellectual property rights, and duplication or sale of all or part of any of the repository collections is not permitted, except that material may be duplicated by you for your research use or educational purposes in electronic or print form. You must obtain permission for any other use. Electronic or print copies may not be offered, whether for sale or otherwise to anyone who is not an authorised user. 


\title{
Theoretical and pedagogical perspectives on orchestrating creativity and collaborative learning
}

\author{
Hämäläinen Raija ${ }^{1 *} \&$ Katja Vähäsantanen ${ }^{2}$
}

\author{
Corresponding Author ${ }^{*}$ \\ Finnish Institute for Educational Research ${ }^{1}$, University of Jyväskylä \\ P.O.Box 35 \\ Street address: Keskussairaalantie 2 \\ FI-40014 University of Jyväskylä \\ Tel +358 142603301 \\ Fax +358 142603201 \\ raija.h.hamalainen@jyu.fi \\ Department of Educational Sciences ${ }^{2}$, University of Jyväskylä \\ P.O. Box 35 (Viveca 483) \\ FIN-40014 University of Jyväskylä \\ Phone: +358142601679 \\ katja.vahasantanen@jyu.fi \\ Postprint version of \\ Hämäläinen, R. \& Vähäsantanen, K. (2011). Theoretical and pedagogical perspectives on orchestrating \\ creativity and collaborative learning. Educational Research Review, 6(3), 169-184. \\ http://dx.doi.org/10.1016/j.edurev.2011.08.001
}

\begin{abstract}
The role of teacher is increasingly related to designing and arranging collaborative learning situations in which fruitful and creative group work may occur. This thematic review presents recent studies on creativity and collaborative learning from the perspective of the teacher as conductor of learning processes. The precondition for the design and orchestration of these kinds of learning situations is analysing and understanding of creative and collaborative processes and their contextual adaption. Thus, the first section of this review focuses on the theoretical vantage points of creativity and collaborative learning mainly from socio-cultural perspective. Based on this theoretical grounding, the second section describes principles for orchestrating productive collaborative learning and supporting creativity from the teacher's perspective. We discuss three dimensions related to how teachers can bring about collaborative learning and creativity: (1) general pedagogical bases, (2) teachers' pre- and real-time activities and (3) opportunities and challenges for teacher activities. The review is concluded with theoretical and practical implications regarding collaborative learning and creativity.
\end{abstract}

Keywords: collaborative learning, creativity, orchestrating learning, sociocultural approach, teachers' working methods

\section{Introduction}

In a continuously changing information society, technological and social innovations are seen as the engines for economic growth and competitiveness, and as the main prerequisites for welfare (Andiliou \& Murphy, 2010; Florida, 2002). One way to promote these innovations is to 
support creativity and collaboration in learning and working practices (Sawyer, 2006a; Shalley \& Gilson, 2004). In particular, the need for collaborative knowledge construction and divided creative problem solving is suggested to be increasingly essential because future working life is apparently becoming more and more complicated. More often, employees participate in various work processes and communities inside and across work organisations and professions (Billett, 2006; Kirpal, 2004). Work is thus based on inter-professional expertise and the shared construction of new knowledge, and there is a need to improve communication to reach shared understandings, processes and work principles in interagency work (Billett, 2008; Collin, Paloniemi, \& Mecklin, 2010). The needs of current working life and society (e.g. the increasing amount of information available via the internet) also set new challenges for learning and teaching in educational contexts. Thus, $21^{\text {st }}$-century skills (Silva, 2008; Wells \& Claxton, 2002) call for flexible and novel abilities in shared working practices. Therefore, the aim of education is not only to enhance the development of specific knowledge and skills, but also to support and teach collaboration and divided creative problem solving among students (Arvaja, Hämäläinen, \& Rasku-Puttonen, 2009; Craft, 2008; Sawyer, 2006a; Wells \& Claxton, 2002). Against this background, the significance of both collaborative learning and creativity is generally confessed. Further, supporting creativity and collaboration is often set as the target in educational settings. However, typically, it is not defined specifically to which type of learning activities and processes they refer or how they should be supported. Nor do teachers necessarily find pedagogical support for their decisions and teaching activities from curricula (Voogt, 2008). Moreover, even though there are effective ways of supporting collaborative learning and creativity, it is often problematic to enforce research findings from specific conditions (e.g. special laboratory settings) in various authentic learning contexts (e.g. Brown, 1992; Kollar, 2010) or to reach productive collaboration and creativity in authentic classroom situations (e.g. Arvaja, 2007; Sawyer, 2006a).

Challenged by this situation, the present review addresses how to orchestrate collaboration and creativity in authentic educational settings from the teacher's perspective. The precondition for designing and organising collaborative learning and creativity is to analyse and understand collaboration processes and their contextual adaptation. Therefore, in the first section of this review, we describe theoretical vantage points for creativity and collaborative learning. In the second section, we illustrate principles for orchestrating collaborative learning and creativity. Orchestration (teachers' pre- and real-time activities that are grounded by research findings) has recently been widely put forward as a solution for arranging collaboration in naturalistic learning situations (Dillenbourg, Järvelä, \& Fischer, 2009; Kollar, 2010; Mercer, Hennessy, \& Warwick, 2010). A common feature of orchestrating learning is that it draws systematically on research-based productive collaborative learning situations in the design and real-time implementation of teaching. Overall, in this review, we thematically focus on recent studies and discussion on creativity and collaborative learning as a grounding for the productive orchestration of these processes. However, it should be noted that from the teacher's perspective, there are concepts such as 'scaffolding' in the literature that are almost synonymous with orchestrating in terms of pre- and real-time activities in enhancing collaboration and creativity (see, e.g. Scardamalia \& Bereiter, 2006; Stone, 1993; Wood, Bruner, \& Ross, 1976).

\section{Review methods and criteria}


This thematic review presents recent research on creativity and collaborative learning from the perspective of the teacher as conductor of learning processes. In this article, we mainly adopt a sociocultural perspective to synthesise and reflect on research, with a particular focus on enhancing the emergence of creativity and collaboration. The main aim of the article was to explore the understanding of these issues (see Attride-Stirling, 2001) as grounding for teachers in need for finding new ways to orchestrate collaboration and creativity. Since research areas related to creativity and collaboration are very extensive (e.g. a 28.1.2011 online database search of ScienceDirect included 320,842 articles [of which 304,504 were in journals] found for the search term collaboration or creativity), the aim of this review was not to cover these topics inclusively. Rather, the study aimed to establish theoretical and pedagogical perspectives into orchestrating creativity and collaborative learning as grounding for teachers' activities in enhancing $21^{\text {st }}$-century skills. In addition, as the concepts of creativity and collaborative learning are typically used in different research contexts, the aim here was to seek conceptual differences and similarities between these concepts. Overall, a thematic review was considered most appropriate in choosing the relevant research, since its advantage is flexibility in reflecting these remarkably frequently discussed phenomena, i.e. creativity and collaborative learning, from the teacher's perspective (see Braun \& Clarke, 2006).

In qualitative thematic analysis there is particular concern with the reliability in choosing the most relevant literature. Selection was here grounded on active following of the discussion in the research societies investigating creativity and collaborative learning. The aim of choosing 193 cited references of this article was to be analytic (but not rigid) and illustrative of the phenomena, and productive from to point of teachers as orchestrator of creative collaboration (see, also Altheide, 1987). In addition, synthesis was mainly execute from the viewpoint of socio-cultural approach. Analysis was adapted from identification of thematic analysis by Attride-Stirling (2001), and Braun and Clark (2006), including three main phases of investigation.

Firstly, concepts of creativity and collaborative learning were investigated to make sense beyond imitating meanings. In other words, we analysed the literature in order to find basic themes related to these phenomena. After reading and analysing the literature, we identified two basic themes, which were in both cases (creativity and collaboration) the process of its emergence and the outcomes of this process. Secondly, these themes were compared and reorganised to identify theoretical sophistications and relationships of the two constituting concepts (creativity and collaboration). In these phases, we ultimately utilised 109 references. In the third phase of analysis, we addressed literature on orchestrating collaborative learning and creativity from the pedagogical perspective. After close reading and re-reading, three dimensions from literature related to how teachers can orchestrate collaborative learning and creativity were identified as topical. They were as follows: (1) general pedagogical bases, (2) teachers' pre- and real-time activities and (3) opportunities and challenges for teachers' activities. Related to these dimensions, we also specified particular themes. In terms of general pedagogical bases for orchestration, the principal as well as contradictory themes were freedom and structure (34 references were exploited). Teachers' pre- and real-time activities were linked to the main themes, including task structure, interactions and learning resources (53 references were utilised). Related to opportunities and challenges for teacher orchestration activities, the themes determined were teachers' individual/internal resources and the sociocultural context for the different resources (36 references were exploited). 
In order to increase the quality of our thematic review, the analysis occurred through the close collaboration of the authors. During the analysis, we also actively discussed and reflected on the selected topics, dimensions and themes with colleagues in the areas of collaboration and creativity. However, there are limitations on the ability to identify relevant studies. A critical issue in this article is that the cited literature does not explicitly cover all the literature concerning creativity and collaborative learning. The reason for this is that we sought to illuminate the general picture of these phenomena as grounding for teachers' activities, as well as to evoke critical debate in relation to complementary knowledge on enhancing shared group processes. On the other hand, a concomitant strength of this study is that wide-ranging approaches such as this are needed in the educational sciences to help teachers to support creative knowledge construction in various educational settings.

\section{Section I: Theoretical vantage points for creativity and collaborative learning}

In this section, theoretical vantage points are further elaborated on to demonstrate their value for orchestrating creativity and collaborative learning. Research in these areas is mainly grounded on Piaget's (e.g. 1926; 1980) constructivist theory and Vygotsky's (1978) sociocultural approach. Thus, studies of collaboration and creativity often lie between educational psychology-oriented research perspectives (studies of individual cognition) and socioculturally oriented research perspectives (studies of group processes) (Dillenbourg, 2006; Dillenbourg et al., 2009; Moran, 2010; Sawyer, 2006a). In both traditions, the focus has firstly been on the actions of individuals (the creativity and learning of individuals). Next, the focus shifted to include group processes. Against this background, we firstly review the historical roots of individual creativity and the bases for socially divided creativity. Secondly, we present theoretical views of collaborative learning. In particular, we focus on sociocultural perspectives and how social structures and meditational tools (e.g. language, media, technology) shape groups' knowledge construction processes (Wells \& Claxton, 2002; Wertsch, Tulviste, \& Hagstrom, 1993).

\subsection{Creativity: Individual and collaborative perspectives}

Most researchers agree that in creativity, there is always some new, significant and appropriate idea, understanding, information, approach or solution to a problem that emerges from an individual person, group or community (e.g. Craft, Cremin, Burnard, \& Chappell, 2007; Kampylis, Berki, \& Saariluoma, 2009; Sawyer, 2006b; Sternberg \& Lubart, 1999). Thus, originality alone is not a sufficient criterion for creativity. Added to this, the output must be reasonable and useful for other persons. In line with this, Amabile (1997) understands creativity as the generation of appropriate and novel ideas or solutions. When examining the significance of the processes and outputs of creativity, these can be divided into three dimensions: a little c (creativity), middle c (creativity), and big C (Creativity) (see Eteläpelto \& Lahti, 2008; Moran, 2010). The metaphor 'little c' is used when speaking of creativity at the individual level and considering how new understandings, ideas, practical solutions or products are created by a person, and the production is shared and accepted at most by a few other people (Craft, 2003; Moran, 2010). In other words, the output is significant to the individual itself, but not necessarily to many people or to society. In contrast to this, 'big C' refers to processes in which something historically, socially and universally new or valuable emerges, such as the meaningful inventions that have been created in the history of 
humankind (Boden, 1990). Between these opposites on the scale, the concept of 'middle c' is used to refer to a new product or idea created in a certain organisation or small community as a result of group collaboration (Moran, 2010; see also Eteläpelto \& Lahti, 2008).

The roots of the of creativity research concern the psychological origin of individual creativity (see Sawyer, 2006b; Sawyer \& DeZutter, 2009). At the first stage, creativity was connected to the personal properties of the individual (e.g. Guilford, 1950). It was found that creativity is connected especially to the individuals' intellectual abilities (e.g. Barron \& Harrington, 1981). Furthermore, it was identified that creative persons had excellent abilities in terms of independence, originality, risk taking, intuitiveness, flexibility, handling of uncertainty and internal motivation (Barron, 1999; Tardif \& Sternberg, 1988). Later, the conceptions of creativity developed further. In particular, since the 1980s, research has focused on the influence of the environment and its social, cultural and material properties on the creativity of individuals. For example, Amabile (1983) studied how social structures contribute to subjects' motivation and further creativity. According to this author, in order to be creative, three properties must be present: natural motivation, sufficient knowledge and abilities (domain-relevant skills) and inventiveness (creativity-relevant processes). Furthermore, creative persons must have competence when it comes to flexible problem solving, the ability to create new ideas and the capacity to concentrate on long-range working. Moreover, according to Csikszentmihalyi (1988), individual creativity is situated within a field of other actors and customs of the field. This means that in creativity, the individual's resources bind to his or her prior knowledge from the field and the new outputs are evaluated, estimated and approved by other members of the field.

From the 1990s, the second wave of the creativity research began to emphasise this concept as a social and collaborative phenomenon. Thus, recent studies have increasingly highlighted the sociocultural and collective aspects of creativity (see Sawyer, 2006b; Sawyer \& DeZutter, 2009). According to this perspective, creativity involves situated interaction processes with other members working with the topic that are mediated by the present context (e.g. tools, forms and technologies) (Glăveanu, 2010; John-Steiner, 2000; Miell \& Littleton, 2004; Paulus \& Nijstad, 2003; Sawyer, 2006b). The roots of shared creativity are mainly found in the sociocultural approach inspired by Vygotsky (1978). According to Moran and John-Steiner (2003), the work of Vygotsky can be considered as path breaking from the point of view of defining collaborative dimensions of creativity. Creativity, then, is seen as a process that takes place especially in the collaboration between people and is intertwined with the present environment and culture (see Glăveanu, 2010). The sociocultural approach emphasises that insights and ideas must be new and socially suitable, and considered, at least in the community, to be creative (Sawyer, 2006b). During the last few years, creativity researchers have focused on the origin and existence of collaborative creativity. At their best, the different roles of group members, including mutual explaining and shared knowledge construction, have been seen to enable new creative processes and outputs (Grossen, 2008; Sarmiento \& Stahl, 2008; Sawyer, 2006b). All in all, creativity is understood here as a collaborative process (Moran, 2010) in which the members of the community produce a new and useful output (an idea, understanding or solution) for the group or wider community, and different social resources and tools related to collaboration can promote creativity.

\subsection{Collaborative learning: Perspectives of individual vs. collaborative learning}


Current research on collaboration stems partly from earlier work on group-based learning approaches (see Qin, Johnson, \& Johnson, 1995; Springer, Stanne, \& Donovan, 1999). Research on small groups has a long history within social psychology, and has engendered research on cooperative learning. In the latter research area, a task is often split into subtasks among participants and each participant is responsible for a portion of the problem solving; finally, these subtasks are combined into a joint output (see Qin et al., 1995; Stahl, Koschmann, \& Suthers, 2006; Wertsch, 1998). However, in later researcher, the focus has shifted to collaboration, in which the main idea is that participants construct the work 'together' as a shared knowledge construction process (Dillenbourg, 1999; Kneser \& Ploetzner, 2001; Sawyer, 2007; Sawyer \& Berson, 2004). Traditionally, research on collaborative learning took place among educational psychology-oriented research perspectives and socioculturally oriented research perspectives (Dillenbourg, 2006; Dillenbourg et al., 2009). Educational psychology-oriented research perspectives typically focus on how effective different collaboration interventions are for individual learners, while socioculturally oriented research perspectives focus on group learning and the social context in which collaboration emerges. Thus, in both approaches, the potential of collaborative learning is that it combines individual and social processes (Dillenbourg et al., 2009). Moreover, according to Lazonder et al. (2003), both views highlight the importance of engaging in shared knowledge construction in collaborative learning (Cohen, 1994; De Wever, Schellens, Valcke, \& Van Keer, 2006; Jordan \& Henderson, 1995; Kumpulainen \& Mutanen, 2000; Roschelle \& Teasley, 1995). This article is in line with the notion of Arvaja, Salovaara, Häkkinen and Järvelä (2007), according to whom collaboration is defined as a shared knowledge construction in which it is not enough that participants cumulatively share knowledge together (Mercer, 1996), but where the knowledge construction needs to be jointly built on others' ideas and thoughts (Mercer, 2010). The aim of this is for the activities that members of collaborative group engage in to be not individual activities, but rather interdependent group processes (e.g. interactions) attempting to come to a shared conception of a problem (Bereiter, 2002; Roschelle \& Teasley, 1995). Furthermore, in the sociocultural perspective, these shared processes are mediated by the community and social context in which the group work is occurring (Sawyer, 2007; Stahl, 2006).

Collaborative learning (see Bruffee, 1999) is not an unambiguous pedagogical model or method, and there is no unified theory of collaboration (Arvaja, Häkkinen, \& Kankaanranta, 2008; Crook, 1994; Dillenbourg et al., 2009; Littleton \& Whitelock, 2005; Stahl, 2003). Moreover, according to Suthers (2005), different concepts of collaboration are superficially similar (e.g. knowledge building and collaborative knowledge construction; see Arvaja et al., 2007; Scardamalia \& Bereiter, 1991). This article is in line with the Suthers' (2005) clarification that knowledge construction recognises that individuals create their worldview; this meaning-making is more specifically located in a group context in collaborative knowledge construction (see Arvaja et al., 2007). In the area of intersubjective learning, it is further specified that the process of meaning-making is itself constituted of social interactions (Suthers, 2005); finally, knowledge building requires that this group-based meaning-making is being done intentionally (Scardamalia \& Bereiter, 2006). However, even in the research context, it is necessary to differentiate these concepts at a fine-graded level. It should be noted that in authentic classroom situations, these collaborative learning processes are overlapping, and in practice, teachers may apply knowledge produced in various research traditions while orchestrating learning. 
According to Arvaja and colleagues (2008), at the general level, a common feature for collaboration is active and joint construction of shared understanding, meaning, knowledge and expertise among the group or community (see also Gee \& Green, 1998; Pea, 1994; Newman, Griffin, \& Cole, 1989). In collaborative learning (see Crook, 1998; Roschelle, 1992), group learning takes place by distributing participants' own thoughts and expertise, by listening to and elaborating on the views of the others and by the creative and shared knowledge construction of different thoughts and conclusions to reach common goals (Roschelle \& Teasley, 1995; Sawyer, 2007). In other words, the aim is that, in addition to the individual learning goals in successful collaborative learning, group members negotiate and adopt new, shared goals; shared goals may in turn lead to a broader shared understanding (Kneser \& Ploetzner, 2001; Puntambekar \& Young, 2003). In relation to individual working, the advantage of working in the group is the possibility of outsourcing and developing ideas further (Hämäläinen \& Häkkinen, 2010). At its best, collaborative learning (see Littleton \& Häkkinen, 1999) is a shared and creative knowledge construction process between team members committed to the divided evaluation of the learning process (Barnes \& Todd, 1995; Sawyer, 2003; Wells \& Arauz, 2006). Moreover, successful collaboration may evoke positive dependency between team members. In this kind of ideal collaboration (see Vass \& Littleton, 2009), a group creates something that exceeds what any one individual could achieve alone (Stahl, 2004).

As stated previously, at its best, collaborative learning is the joint construction of shared meaning, understanding and knowledge, based on elaboration and evaluation of other group members' ideas and thoughts (Arvaja, 2007; Littleton \& Whitelock, 2005; Van Boxtel, Van der Linden, \& Kanselaar, 2000; Webb \& Palincsar, 1996). Therefore, collaboration is typically described based on certain types of a) shared learning processes such as joint creation of understanding (Barron, 2003; Littleton \& Whitelock, 2005), knowledge building (Scardamalia \& Bereiter, 1991; Scardamalia \& Bereiter, 2006), constructing group cognition (Stahl, 2006), collaborative co-construction (see Reusser, 2001) of knowledge (e.g. Baker, 2002), shared knowledge construction (Arvaja et al., 2008), conceptual knowledge construction (Krange \& Ludvigsen, 2008), intersubjective learning (Suthers, 2005), constructing shared understanding (Puntambekar \& Young 2003) and collective thinking (Baker, 2010), and/or b) shared learning activities such as coordination (Barron, 2000), negotiation of shared meanings (Miell \& Littleton, 2004; Miell \& Littleton, 2008; Pea, 1993), elaboration and coelaboration (e.g. Baker, 2003; Hamilton, 1997), argumentation (Andriessen, 2006; Leitão, 2000; Marttunen, Laurinen, Litosseliti, \& Lund, 2005), explaining (Sandoval, 2003), mutual explaining (e.g. Webb, 1989; Webb \& Palincsar, 1996), observation of problem solving (Barron, 2003), questioning (Chin, 2002), providing and receiving constructive criticism (Sawyer, 2007), synthesizing multiple perspectives (Bielaczyc \& Collins, 2006) or reasoning (e.g. Cobb \& Yackel, 1996; Mercer, Dawes, Wegerif, \& Sams, 2004; Resnick, Salmon, Zeitz, Wathen, \& Holowchak, 1993). However, a collaborative activity (e.g. argumentation) alone in an educational environment does not automatically produce cognitively high-level learning (Dillenbourg, 2002). Rather, learning is affected by the quality of shared processes (and/or activities) and whether a group is able to build new and novel knowledge or improve shared conceptual understanding through such interactions (Barron, 2003; Krange \& Ludvigsen, 2008). This kind of building new and novel knowledge or understanding is a complex phenomenon, and different aspects of learning - such as cognitive, social and motivational elements—are often intertwined in successful collaboration (Hämäläinen \& Häkkinen, 2010). 


\subsection{Creativity and collaborative learning: Theoretical overlaps and differences}

Prior research has pointed to overlapping elements of collaborative learning and creativity. Sawyer (2003) has argued that creativity and learning involve the same mental processes, and significant creations are almost always the result of complex collaborations (Sawyer \& DeZutter, 2009). In practice, for example, in the research tradition on collaborative 'knowledge building', members of a knowledge-building community are understood as intentionally aiming towards knowledge as a social product by expanding the boundaries of their knowledge, reflecting on and choosing activities that address limits of their understanding (see Scardamalia \& Bereiter, 1996; Stahl et al., 2006); this is very close to the notion of (middle c) creativity. Indeed, there is congruence between successful collaborative knowledge construction and creative collaboration (Eteläpelto \& Lahti, 2008). It is generally agreed that theoretical knowledge resources can be applied to evoke the creative collaboration processes and effective knowledge work of groups (and/or communities) within various contexts (e.g. Kollar, Fischer, \& Hesse, 2006; Sawyer, 2007; Scardamalia \& Bereiter, 2006; Zhang, Scardamalia, Reeve, \& Messina, 2009). However, although there are similarities and overlaps between the concepts, creativity and learning are not simply one and the same thing in all contexts. It has been argued that sometimes the difference is blurry, even within the research context focusing on these processes. Therefore, there is the ongoing challenge of developing a better understanding of creativity and 'effective collaborative learning' (Craft, 2008), as both research traditions have been able to produce supplementary knowledge of productive group interaction. Although collaborative learning and creativity (creative collaboration) can be understood as overlapping and similar concepts, we make the following distinction between them.

A constructivist approach to learning is very close to the notion of creativity-the generation of novel, useful ideas and outcomes using imagination on a spectrum of individual and collaborative activity (Craft, 2008). Furthermore, both collaborative learning and creativity are divided, interactive and culturally shared processes. Both involve novelty, but not in the same way. Learning means 'new for learner(s)'; creativity means 'new also for the domain (in practice this means no one else in the culture has yet thought about the topic in that way)' (Moran, 2010). Therefore, the difference between the concepts relates to the novelty and usefulness of a process or output for the group itself or the surrounding community. In other words, while the goal of collaborative learning is to enhance understanding (build new and novel knowledge for the group itself) through shared knowledge construction (Arvaja et al., 2007), the goal of creative collaboration is to produce a process of novel outputs, at least at the community level (Eteläpelto \& Lahti, 2008; Moran, 2010). Thus, at the group level, collaborative creativity exceeds collaborative knowledge construction, as something novel to the surrounding community has to be created (at least at the middle c level). In contrast, in practice in a collaborative learning situation, it is enough that a group of learners builds new knowledge based on others' ideas and thoughts (Arvaja, 2007) (e.g. something they would probably not have been able to achieve alone), but in most cases, someone else in the culture already knows the fact or how to do the task (Moran, 2010). However, it is possible that at their best, in collaborative learning situations, groups may reach collaborative creativity and generate novel outputs or processes meaningful to the surrounding community. Indeed, according to Moran (2010), creativity and learning should neither be set in opposition nor equated with each other, but are rather coordinated processes that have a symbiotic relationship (Beghetto \& Kaufman, 2007; Moran, 2010). 
In this second section, we have focused theoretically on collaborative creativity and learning, which can be used to enhance collaborative learning and the development of creativity in different educational settings. In the next section, we illustrate how to orchestrate collaborative learning and creativity in naturalistic learning situations, which may also be technology enhanced (see Koschmann, 1996). We see that there is a need to ground teaching in theoretical knowledge to support the changing role of the teacher from monologic to dialogic actor, which includes orchestrating, scaffolding, supporting and structuring students' shared knowledge construction processes (Craft, 2008; Dillenbourg et al., 2009; Fischer \& Dillenbourg, 2006; Sawyer, 2006b; Scardamalia \& Bereiter, 2006; Wells \& Arauz, 2006). In other words, teachers need to facilitate shared knowledge construction processes in various learning situations. In particular, we next demonstrate how teachers can orchestrate complex learning processes in terms of freedom and structure, and by utilising the appropriate tools, tasks and resources to support learners in their knowledgeconstruction processes. We also discuss the opportunities and challenges that teachers face in this orchestration.

\section{Section II: Principles for orchestrating: The teacher's perspective}

This review is in line with the notion that the orchestration metaphor has the potential for stimulating future practice and research on enhancing learning processes (Kollar, Hämäläinen, Evans, De Wever, \& Perrotta, 2011). The main idea of the orchestration is to combine design and improvisation. The curriculum sets the starting points for activities, the learning environment supports collaboration and the teacher pre-designs the structure for learning processes as well as orchestrating them in real time (based on research findings of productive collaboration); the learners are then given enough freedom for shared knowledge construction (Dillenbourg \& Jermann, 2010; Kollar et al., 2011). The focus here lies between sociocultural approaches and instructional design (Dillenbourg \& Tchounikine, 2007) on how to orchestrate learning based on understanding these processes and their contextual adaptation. Below, we present and discuss three dimensions related to how teachers can orchestrate collaborative learning and creativity: (1) general pedagogical bases, (2) teachers' pre- and real-time activities and (3) opportunities and challenges for teacher activities.

\subsection{Pedagogical bases for orchestration}

The concept of orchestrating learning is not new (Brown, 1992). Recently, along with the new emerging needs of society (e.g. inter-professional collaboration) and the development of new technologies (e.g. 3D spaces), orchestration has again become a topical issue in terms of supporting collaborative learning in new ways (see Kollar, 2010; Mercer et al., 2010). From a pedagogical perspective, orchestrating creative collaboration lies at the crossroads of the research on disciplined improvisation (which highlights the emergent nature of effective classroom practice, e.g. Sawyer, 2004) and structuring collaboration (which highlights [research-based] instructional support for collaboration processes, e.g. Dillenbourg \& Tchounikine, 2007; Kobbe et al., 2007). From both perspectives, research has emphasised the significance of teaching as a creative performance (e.g. Sawyer, 2004), the need to leave space for spontaneous richness of collaborative interactions (Dillenbourg \& Tchounikine, 2007) and the meaning of teacher flexibility for students' creativity as opposed to sticking to rigid schedules at school (Ambrose, 2005; Moran, 2010). Related to this, there have been 
different attempts in the literature to enhance creativity and collaborative learning, such as through knowledge building and scaffolding (Davis \& Miyake, 2004; Scardamalia \& Bereiter, 2006; Wood, Bruner, \& Ross; 1976) and structuring collaboration (Dillenbourg \& Tchounikine, 2007; Kollar et al., 2006), as well as the pros and cons for each perspective. Overall, studies are often positioned along a continuum between research perspectives highlighting the importance of structuring (or scripting) collaboration processes (e.g. De Wever et al., 2010) and research perspectives emphasising freedom (Sawyer, 2004). In the current state, educational professionals are realising that, from the viewpoint of teachers, it is important to find a balance between structure and freedom in educational settings.

Even the research highlighting the flexible organisation of learning activities does not mean 'totally free' intuitive teaching without educational goals. Learning cannot be based only on improvisation, because the students must obtain certain skills at a certain time (e.g. Sawyer, 2004). Thus, from a sociocultural perspective, orchestrating learning emphasises the teacher as an important actor in productive collaboration processes (Kollar et. al., 2011; Mercer, Hennessy \& Warwick, 2010), acknowledges the need for a curriculum (Sawyer, 2004) and highlights the need for designing and supporting group learning based on research findings related to productive group processes (Hämäläinen \& Häkkinen, 2010). The idea is that a curriculum sets the starting point for learning. At the general level, the teacher's role is to lead the learning process towards a specific outcome (see also Kollar et al., 2011), and ensure an open and flexible learning environment for collaboration and creativity (Andiliou \& Murphy, 2010). Although there is freedom during the learning activities, the teacher simultaneously supports and monitors the learning processes during the group work based on contextual needs (Arvaja et al., 2009). In practice, the teacher has aims and plans (based on the curriculum and defined beforehand) for lessons, as well as goals he/she creates for learning situations (based on research findings; e.g. solving cognitive conflicts), and presents problems for students to enhance shared and creative knowledge construction (Hämäläinen \& Häkkinen, 2010). In other words, the teacher's role is not only that of facilitator, but also fellow collaborator, joining the students in collaboration processes. This means that teachers as real-time orchestrators should focus on enhancing collaboration processes, including channelling and focusing learning processes (see Pea, 2004), instead of providing correct answers. In practice, this can be done, for example, by applying learning methods that require groups to formulate hypotheses, provide explanations, interpret texts, conceptualise their own experiences through theory and describe observations (Arvaja, 2011; Fleith, 2000; Mercer et al., 2010; Ruiz-Primo, Briggs, Iverson, Talbot, \& Shepard, 2011; Sawyer, 2004; Scardamalia \& Bereiter, 2006). Added to this, Craft (2005) has shown that creativity in classrooms can be supported by involving questioning and challenging, investigating connections and relationships, envisaging hypotheses, exploring ideas and reflecting critically (see also Rejskind, 2000).

Recent studies have suggested that successful orchestration also requires several dimensions other than balancing between improvisation and structure. According to Hämäläinen and Arvaja (2009), successful collaborative learning tasks, not surprisingly, require a genuine need for collaboration and learning (the so-called real group tasks). Added to this, learners have to share enough common ground so that it is possible to form shared knowledge and to handle tensions of opposite and critical views fruitfully (see Brown \& Campione, 1994). In other words, instead of reaching unanimity, the aim is to support critical discussion and evaluation of alternative views through careful guidance by the teacher 
(Dillenbourg \& Jermann, 2007; Doise \& Mugny, 1986; Kollar, Fischer, \& Slotta, 2008; Lahti, Eteläpelto, \& Siitari, 2004; Mercer \& Littleton, 2007; Moran \& John-Steiner, 2004; RojasDrummond, Mazon, Fernandez, \& Wegerif, 2006; Wegerif, 2005). Moreover, creative collaboration requires an emotionally safe atmosphere and the provision of a respectful environment in which differences are critically engaged, but not in a disputational way (Eteläpelto \& Lahti, 2008; Nijstad \& Paulus, 2003).

\subsection{Orchestrating as pre- and real-time activity}

Ruiz-Primo, Figueroa and Gluckman (2011) have suggested that in enhancing creative collaboration, there is a need to emphasise the dialogue between all participants of the classroom rather than just arriving at the correct answer. In practice, this means that students and teachers collaborate to identify problems and alternative methods of finding solutions together (Sawyer, 2004; Scardamalia \& Bereiter, 2006). In line with this, we argue that these productive dialogues do not necessarily emerge unassisted. To allow students to achieve a higher level of understanding (see Stone, 1993), there is a need to pay attention to how to draw systematically on research-based productive learning situations in orchestrating collaboration and creativity; next, we address guidelines for how to orchestrate tasks to achieve these goals based on recent research findings. The focus is on the constituent components of orchestrating collaborative tasks from three perspectives: task structures (open ended, set tasks, structured and unstructured), interactions (research-based interaction beneficial for collaboration) and resources (internal, external and integrated). The relation of these constituent components is interdependence. In the following, we more closely elaborate upon why and how they can be applied in enhancing collaboration and creativity.

Tasks that encourage creative collaboration typically include elements whereby students need to consider alternative solutions, make choices based on evidence, investigate these evidences in different conditions and explore new and even counterpoint issues (Reiser; 2004; Ruiz-Primo, Figueroa, \& Gluckman, 2011; Sawyer, 2007). In terms of task structure, fostering interactions can be supported by different types of tasks. The collaborative group tasks can vary from open-ended problems (e.g. Nijstad \& Paulus, 2003; West, 2003) to set tasks with one correct solution (Hämäläinen, Oksanen, \& Häkkinen, 2008), and/or from unstructured tasks with no clear-cut procedures or answers (Cohen, 1994; Sawyer, 2004) to structured tasks with detailed instruction (e.g. Weinberger, Ertl, Fischer, \& Mandl, 2005). While it has been quite generally argued that creative collaboration should be embedded in various subject areas (e.g., Craft, Jeffrey, \& Leibling, 2001), there are opposing research findings on the use of different task structures. Researchers have indicated that success and failure in collaboration may occur within each kind of task, depending on contextual necessities. For example, on the one hand, Cohen (1994) has highlighted the use of ill-structured tasks in enhancing creative collaboration; on the other hand, Arvaja, Häkkinen, Eteläpelto and Rasku-Puttonen (2000) have reported problems in collaboration processes while solving ill-structured tasks. Added to this, while Stegmann, Weinberger and Fischer (2007) have indicated the positive influence of well-defined task structures, in contrast, Hämäläinen and Häkkinen (2010) have reported problems in collaboration while solving 'over-structured' tasks. Therefore, it seems that it is not possible to define 'ideal' tasks without contextual knowledge. 
Related to the complexity of choosing the right task for different learning situations, it has been assumed that collaboration is especially needed for tasks in which one can end up (through the critical discussion of different points of view) at several different conclusions (e.g. Vass \& Littleton, 2009). Collaborative creativity then comprises both the debate on alternative ideas and solutions and the selection of the best idea. Hence, Nijstad and Paulus (2003) argue that collaboration is not even necessary in set tasks with one correct solution because, in that case, the knowledge construction of the individual group member may be sufficient for solving the problem set. On the other hand, conflicting results have again been obtained, and it has been argued that collaboration can also be effectively utilised in tasks with only one correct solution (e.g. Hämäläinen et al., 2008). Thus, it is essential that tasks truly require cognitive diversity (Hämäläinen, 2011), and collaboration needs to be grounded on making choices or predictions on the basis of evidence (see Ruiz-Primo, Figueroa, \& Gluckman, 2011). Against this background, Ruiz-Primo, Figueroa and Gluckman (2011) have suggested that the composition of the group may be applied as a practical, theoretically grounded way of evoking conditions for making interactions more productive. Thus, the heterogeneity of the group, for example different interests, levels of knowledge and understandings (Kneser \& Ploetzner, 2001), backgrounds, genders (Webb, 1984) and skills may be applied successfully in evoking creative collaboration processes. The potential of heterogeneity is that (at its best) it creates dependency on the differences of the members (De Laat \& Lally, 2004). Thus, in a heterogeneous group, it is more probable that the members will bring unique knowledge, skills and expertise to the group (which enables the finding of several alternative solutions, along with new knowledge and understandings) (Nijstad \& Paulus, 2003). The task then encourages learners to compare and study different points of view on the same phenomenon. All in all, cognitive diversity may be increased to enhance collaborative learning (Schellens, Van Keer, De Wever, \& Valcke, 2007) and creativity (Sawyer, 2004).

As Azmitia (1996) puts it, social interaction leads to the creation and revision of new knowledge. Thus, one promising approach to orchestrating learning is to focus on how to foster interaction on collaborative tasks (see also Scardamalia \& Bereiter, 1991). In line with that, Sawyer (2004) has categorised the focus of researchers who study collaborative learning into three aspects of interaction: a) providing and receiving explanations (e.g. Webb, 1984), b) a mediating role of solving conflict and controversy (e.g. Doise \& Mugny, 1986) and c) jointly building knowledge on each other's ideas and thoughts (e.g. Palincsar \& Brown, 1984; Scardamalia \& Bereiter, 2006). These aspects may be applied as recourses for orchestrating collaboration. Supplementarily within computer-supported collaborative learning (CSCL) research society research interest has focused on structuring or scripting collaborative interactions as a particular kind of instructional approach to support collaboration (for more detail, see Kobbe et al., 2007; Kollar et al., 2006). Thus, different kinds of design principles have been used successfully to foster specific interactions. So far, scripting has been mainly investigated based on using a) complementary information (e.g., variants of Jigsaw; Aronson et al., 1978), b) reciprocal activities (see Palincsar \& Brown, 1984) or c) solving socio-cognitive conflicts (Doise \& Mugny, 1986; Piaget, 1985) as a grounding for arranging collaborative interactions.

Recent critical studies have suggested that especially in technology-enhanced learning settings, there is the problem of reducing (or even negating) the role of teachers in supporting collaboration (Dillenbourg \& Jermann, 2010), as the focus has typically been on 
enhancing interactions in virtual environments without real-time teacher support. Orchestrating learning aims to supplement this approach by teachers' timely support, and to focus on flexible ways of arranging creativity and collaboration. This means that tasks should be designed based on research findings regarding the cognitive, social and motivational effects of creativity and/or collaborative learning. The aim is then to design the learning situation to encourage learners to challenge themselves in shared knowledge-construction processes with the support of learning resources and teacher scaffolding (Gall \& Breeze, 2008; Hämäläinen \& Häkkinen, 2010; Jeong \& Hmelo-Silver, 2010; Mercer et al., 2010; Palincsar \& Brown, 1984). In practice, this means that, for example, a mediating role for solving conflict and controversy can be created by providing student materials with conflicting evidence (e.g. theories of collaborative learning from different perspectives, like sociocognitive v. sociocultural points of view) (see Valleala, Arvaja, \& Hämäläinen, 2010) or by asking them to play conflicting roles (e.g. the representative of the Association for Nature Conservation v. the representative of the industry to discuss the future of nuclear power). In this way, the members of the group need to explain different points of view, argue their own position and negotiate to find the joint solution (see also Sandoval \& Reiser, 2004). In addition, needed groups can then be offered support and fellow collaboration with the teacher in terms of interaction, communication, negotiation, co-construction and revising knowledge, for example by asking open-ended questions and catalysing group progress (see also Hmelo-Silver \& Barrows, 2008).

According to recent research, different learning resources can be used to orchestrate interactions and task structures. First, external resources (e.g. books, internet, technological solutions) provided by teachers (Jeong \& Hmelo-Silver, 2010) and/or internal resources such as learners' previous experience (Arvaja et al., 2007) have been beneficially used to enhance shared knowledge construction (Arvaja, 2007), increase the significance of the learning to the learners (Craft, 2005) and improve students' conceptual understanding of different disciplinary issues (Krange \& Ludvigsen, 2008). At their best, external resources like the utilisation of technology are valuable in enhancing collaborative learning (De Corte, 1996; Dillenbourg et al., 2009; Scardamalia \& Bereiter, 1991; Scardamalia \& Bereiter, 1994; Littleton \& Whitelock, 2005; Webb, Ender, \& Lewis, 1986). For example, it is possible to pay attention to shared knowledge-construction processes (Arvaja, 2007), shape the way learners interact with one another, e.g. with collaboration scripts (see Kobbe et al., 2007) and offer more illustrative environments for shared knowledge construction (Hämäläinen, 2008). While the research has mostly focused on the use of external learning resources (e.g. technological solutions), the rising trend is to pay attention to the use of internal resources as well (for example, the learners' interests and backgrounds) (see Arvaja, 2007) in designing and orchestrating creative learning (Craft et al., 2007; Troman, Jeffrey, \& Raggl, 2007). As a result, creativity and collaboration, for example, can be supported by the conflicting or complimentary interests of different group members. Moreover, the advance in the use of internal resources offers the possibility to highlight the relevance and significance of the learning to the learner's life, culture and interests. The more teaching relates to the life and culture of the learners, the more they can control the learning processes, and the more they probably experience internal motivation and enthusiasm; ultimately, therefore, creative learning outcomes will emerge (Craft, 2005; Troman et al., 2007).

In conclusion, different learning resources can be used effectively to orchestrate learning. Thus, we propose that when internal and external resources are investigated from the 
perspectives of different actors (whole group, small group, individual learners and teachers), many resources can be seen as integrated resources that combine internal and external elements. For example, a picture may be investigated as external resources for knowledge building (e.g. in geography); on the other hand, the same picture may represent an internal resource of the personal experience of the group, individual learner and/or teacher. Finally, emotional, mental and intellectual resources influence how different resources are interpreted by group members in the shared knowledge construction process (Eteläpelto \& Lahti, 2008; Moran, 2010). We now move to a discussion of what kinds of opportunities teachers can utilise and what kinds of challenges they can meet when they orchestrate students' collaborative creativity and learning.

\subsection{Opportunities and challenges for teacher orchestration activities}

Previously, we proposed that orchestration needs to be grounded by theoretical knowledge. It should be added that successful orchestration is related to vocational competencies and teaching strategies (Andiliou \& Murphy, 2010; Moran, 2010; Piirto, 2004; Vähäsantanen, 2009). Thus, there is a need to know the theories and contents of the learning and sense the contextual needs of the learning situation. As the artist must know the painting techniques before the creative painting can emerge, the teacher must have sufficient pedagogic expertise to orchestrate successful collaborative learning. Furthermore, teachers' own professional interests, attitudes, beliefs and goals are intertwined with how they design and orchestrate collaborative learning situations in which creative outcomes can emerge (e.g. Andiliou \& Murphy, 2010; Craft et al., 2007; Moran, 2010; Vähäsantanen, 2009).

Teacher attitudes towards innovative ways of working, such as providing encouragement and freedom, as well as allowing for risk-taking and collaboration, can prepare and facilitate students' creativity (Torrance, 1965). In particular, teachers' attitudes and teaching strategies are the two factors that determine how supportive of creativity a classroom environment will be (Andiliou \& Murphy, 2010). Sawyer (2004) emphasises that fostering students' collaboration and creativity is related to the age and competencies of teachers. At their best, expert teachers use routines and activity structures more than novice teachers, but they are also able to invoke and apply these routines in a creative, improvisational fashion. In this way, teachers develop a repertoire of useful routines, and have the professional skills required to instantly assess the flow of classroom improvisation (see also Dillenbourg \& Jermann, 2007) and interject exactly the right routine to advance their pedagogical goals, while allowing the improvisational discussion to continue (Sawyer, 2004; Sawyer, 2006a). Related to this, teachers may apply ways of teaching which enhance autonomy and freedom of learners' knowledge construction while working, and which allow enough time for creative thinking and collaboration processes (Cropley, 1997; Feldhusen \& Hobson, 1972; Sternberg \& Williams, 1996). However, even for expert teachers, it might be challenging to relate teaching to students' cultures and backgrounds by, for example, spontaneously utilising internal learning resources in orchestrating learning, as a teacher's personal life and interests may be weakly related to young students' culture and preferences (Vähäsantanen \& Billett, 2008). We also claim that utilising teaching methods to reach creativity and collaboration is not merely dependent on the teacher's knowledge and abilities (e.g. how they are able to respond to the needs of the learning), because external administration and work culture also affect the teacher's work. In this context, we will next discuss the main challenges related to external administration and work culture related to orchestrating collaboration and creativity. 
In the context of formal educational, the teacher's actions are mediated by the structural elements of their work settings, such as the resources available to them, the norms of their school, curriculum guidelines and externally mandated policies (Lasky, 2005; Moran, 2010). For example, a fixed and compulsory curriculum which involves a great deal of propositional knowledge and takes up learning time may pose challenges to stimulating creativity and collaboration among students (Andiliou \& Murphy, 2010; Craft, 2005). In practice, an overburdened compulsory curriculum may weaken (or even rule out) opportunities for teachers to introduce collaborative working methods in the classroom context. Furthermore, during the past few years, the control of and external instructions governing the teacher's work have strengthened because of many administrational reforms in education organisations (Day, 2002; Hargreaves, 2000; Meyer, 2002). An administration culture that tightens and creates new conditions for teachers' actions constrains their professional preferences, interests (Vähäsantanen, Hökkä, Eteläpelto, Rasku-Puttonen, \& Littleton, 2008), and creativity (Hodkinson \& Hodkinson, 2003; Sawyer, 2004; Vähäsantanen \& Eteläpelto, 2011; Woods, 2002). Hierarchical and bureaucratic organisations weaken creativity because they restrict the decision making of individuals, reduce the possibilities of influencing their own work and do not encourage the development of new working methods (Shalley \& Gilson, 2004; Vähäsantanen \& Eteläpelto, 2011; West, 2003). Moreover, teachers' work satisfaction seems to be related to opportunities for creativity and autonomy (Sawyer, 2004), and it further appears that teachers leave the educational organisation when there are fewer opportunities to be autonomous and creative (Vähäsantanen \& Eteläpelto, 2011). Therefore, we may wonder if today's and tomorrow's society should highlight the autonomy of teachers' work to a greater extent to enhance professional development and creativity in teaching itself.

The current challenge of orchestrating creativity and collaborative learning is to increase the collegial collaboration between teachers in terms of collective planning and implementing learning. Working alone has typically been connected to the teaching profession, and the collegial collaboration is not yet the most natural way of working within educational organisations (Hargreaves, 2000; Hökkä, Rasku-Puttonen, \& Eteläpelto, 2008; Vähäsantanen et al., 2008). Furthermore, teachers' creativity is challenged if they do not dare to try new working methods or break routines for fear of criticism and punishment (cf. Ambrose 2005; De Dreu \& West, 2001; Shalley \& Gilson, 2004). Thus, shared working methods in encouraging educational origination can increase opportunities for teachers' collaborative creativity, which may further enhance orchestrating creativity and collaboration within various natural learning contexts (Craft, 2005; Moran, 2010). Therefore, it is essential that in future, a collaborative and confidential atmosphere between teachers in educational organisations is created and supported. In practice, support of teachers can be enhanced, for example, by a concrete cooperation time and place for teachers (Vähäsantanen et al., 2008), training to adopt and further develop collaborative working methods (Craft, 2005) and technological solutions to monitor learning situations (Arvaja et al., 2009).

Teachers face social demands for more creative, collaborative and effective education, but they do not feel always well equipped to achieve these goals (Kampylis et al., 2009; Moran, 2010). Hence, educational organisations can offer teachers more concrete resources to design, orchestrate and support collaborative learning and creativity. For example, computational technologies may have a number of helpful functions for orchestrating learning (Kollar et al., 2011). According to Faulkner, Joiner, Littleton, Miell and Thompson (2000), 
computers may have a unique role to play in facilitating shared collaboration processes, and there are number of recent studies indicating the potential for technological solutions in enhancing collaboration (e.g. De Wever, Van Keer, Schellens, \& Valcke, 2010; Kollar et al., 2008). However, the use of technology also sets challenges for the teacher's work (Arvaja et al., 2009), and there are many unrealistic expectations connected to the role of technology (e.g. technology would replace the teacher). In practice, it is typical that, in their current state, technological environments are rarely designed with pedagogical or instructional theories of learning and teaching in mind (Laurillard, 2009), and therefore technology itself does not guarantee collaboration within groups (Bluemink, Hämäläinen, Manninen, \& Järvelä, 2010). Therefore, the potential of technology for future learning relies first on designing new ways to support teachers in orchestrating collaborative learning and creativity, and second, in developing technological environments which require and support definite collaboration in problem solving.

To sum up, we have examined general pedagogical bases, teachers' pre- and real-time activities and current opportunities and challenges for teachers in educational contexts. Teachers need to do their best to inspire, motivate and support students' collaborative and creative learning (Arvaja et al., 2009; Sawyer, 2004). One way to achieve this goal is to orchestrate learning. In doing so, teachers need to organise tasks and successfully utilise available learning resources related to students' specific educational situation. In addition, there is a need to balance flexible structures and scripts with freedom and improvisation. Furthermore, teachers' own internal resources and sociocultural practices create different possibilities and limitations for teacher's work, as well as how they are able to respond to the needs of learning and create successful learning spaces and authentic learning situations with different students.

\section{Conclusion}

It is widely agreed that to support $21^{\text {st }}$-century skills, there is a need to find new ways to enhance collaboration and creativity. The use of collaborative working methods facilitates both solving creative tasks and the development of creativity (Hewitt, 2008; MacDonald \& Miell, 2000). Even complex learning aims can be achieved through shared knowledge construction (Hämäläinen \& Häkkinen, 2010). Moreover, because of these knowledge construction processes, profound understandings, new skills or new ideas may arise (Craft, 2005; Troman et al., 2007). Despite this potential, however, recent studies have shown that in reality, high-level, productive collaboration is relatively rare (Hämäläinen, 2011; Kollar, 2010), and is challenging to 'create' (Dillenbourg \& Jermann, 2010; Vass \& Littleton, 2009). Moreover, in authentic learning contexts, completely free collaboration does not necessarily promote productive collaboration and high-level learning (Dillenbourg, 2002; Sawyer, 2006a). Students need to be guided in how to interact (Ruiz-Primo, Figueroa, \& Gluckman, 2011). Therefore, attention needs to be paid to how to orchestrate learners' working processes to accomplish creative collaboration and learning (Arvaja et al., 2009; Kobbe, et al., 2007; Sawyer, 2006b). This review has been one attempt to answer these challenges. First, we described the theoretical vantage points of collaborative creativity and collaborative learning from sociocultural perspectives and theoretical bases for orchestrating collaboration and creativity. Next, we summarised in theoretical terms the main concurrences and differences between creativity and collaborative learning. Then, we concluded with the practical 
implications for the theoretically grounded orchestration of these shared processes, and revealed obstacles and possibilities related to orchestration from the teacher's perspective.

Research and theoretical discussion are divided into two broad categories: creativity and collaborative learning. These concepts are also typically used in different research contexts. However, there is congruence between the concepts of collaborative knowledge construction and creative collaboration. In terms of a sociocultural approach in particular, collaboration and creativity are understood as divided, interactive and culturally shared processes of different learners in groups (e.g. Sawyer, 2006b). Thus, the terms collaboration and collaborative creativity overlap, and in the research context, they are even used to refer to similar types of shared knowledge-construction processes. In spite of their similitude, collaborative learning and creative collaboration should not be understood as totally corresponding phenomena. We suggest that the main difference between the concepts relates to the novelty value and the usefulness of a process or output for the group or surrounding community. First, when research refers to high-level collaboration, it seems likely that productive collaborative learning comprises at least group-level creativity (novel understanding, ideas or solutions). Second, collaborative creativity exceeds collaborative knowledge construction, as something novel to the surrounding community has to be created. There certainly is indistinctness between the concepts of collaboration and creativity, and we argue for the better conceptual clarity of these concepts in the future. However, we also think that this friction may offer the potential to analyse and productively rethink important issues in orchestrating collaboration, as different research perspectives have been able to produce complementary knowledge relating to the enhancement of shared group processes.

In practice, orchestrating collaborative learning and creativity seems to be a challenging process that balances between curriculum-based design, theory-based knowledge and contextual necessities. Furthermore, in successful orchestration, there is a need to find the balance between individual skills (of learners and the teacher), the abilities of the group and the challenges of the task (Amabile, 1983; Barron, 2003; Csikszentmihalyi, 1990). Therefore, in orchestrating learning, there is a need to pay attention to the task itself and balance between the instructions and 'free processes'. Thus, from a pedagogical perspective, orchestrating creative collaboration lies at the crossroads of research highlighting the emergent nature of effective classroom practices (e.g. Sawyer, 2004) and that on structuring collaboration, for example instructional support for collaboration (e.g. Kobbe et al., 2007). This review is in line with the notion that orchestrating learning must be both pedagogically structured and flexible in order to reach learning goals (Dillenbourg \& Jermann, 2010; Gall \& Breeze, 2008; Sawyer, 2004). Thus, the learning goal (task which the learners' strive to complete) and its contextual needs set the limits for how much learning should be designed and instructed (Arvaja, 2007; Hämäläinen \& Häkkinen, 2010; Kelly, Crawford, \& Green, 2001). This means that when teachers orchestrate collaborative learning and support creativity among students, they need to find the balance between different necessities, such as between design and real-time activity, the interrelationship between instruction and improvisation and the needs of different groups.

In this review, we have focused on the three constituent components of balancing design and real time activity - task structures, interactions and resources - that recent research has indicated as beneficial instructional components for supporting collaboration and creativity. We argue that task structures, interactions and resources are examples of applying 
research-based productive learning situations in authentic learning settings, and hence, promoting creativity and collaboration in educational contexts. Related to these components, for the future, research findings on collaboration roles (see Kneser \& Ploetzner, 2001; Strijbos \& De Laat, 2010) have the potential for orchestrating learning. Moreover, there is yet the under-researched area of different social-planes (individual leaner, small group, class wide and teachers; see Dillenbourg \& Jermann, 2007) and their relation to flexible orchestration. Therefore, in future, orchestrating creativity and collaboration needs to be studied systematically from the perspective of integrating individual, small group, and classwide activities. In addition, there is a need for a better empirical understanding of the role and meaning of emotions in creative and collaborative learning processes, since so far only a few studies (Eteläpelto \& Lahti, 2008; Järvenoja \& Järvelä, 2009) have addressed the emotional dimension of collaborative learning and creativity.

At its best, orchestrating learning seems to offer potential for enhancing collaboration and creativity in different educational settings. From a sociocultural perspective, the role of the teacher is significant in the enhancement of productive collaboration processes. However, research has also shown that how teachers are able to respond to the needs of learners and create successful learning spaces is not merely dependent upon their abilities and professional competencies, since different sociocultural practices create different possibilities for and limitations on the teacher's work activities and creativity. Therefore, in future, more attention needs to be paid to how to support teachers' activities in fostering students' creativity and collaboration. Recent research has indicated factors that influence teachers' abilities to apply creative and collaborative working methods. First, there is a need to highlight the autonomy of teachers' work to enhance professional development and creativity. Second, external administration and the work culture need to support creative and collaborative teaching methods. Third, there is a need to offer teachers concrete resources to orchestrate collaborative learning and creativity. For example, in future the successful utilisation of technology may be one opportunity. Thus, technological solutions can help to realise more participatory modes of instruction which can complement more traditional, teacher-centred instructional approaches (e.g. environments that support collaboration and/or environments that help the teacher to monitor and orchestrate the learning processes). Thus, for the future, it is crucial find more ways to support teachers in developing and applying creative and collaborative teaching methods.

In conclusion, it seems that supporting learning and teaching requires the integration of theoretical, pedagogic and technological development. There is a special need to pay attention to how to engage groups in high-level knowledge-construction processes and how to support teachers. In future, theoretical knowledge about creativity and collaborative learning (for example, knowledge about the processes of shared knowledge constructions) needs to be integrated with the teacher's orchestration of learning activities and bound to the learning context.

\section{Acknowledgements}

The authors would like to thank Professor Karen Littleton for her comments on an initial version of this article and associate editor Professor Keith Sawyer for careful review comments which have significantly helped us to improve the article. We also thank the collaboration partners on the Stellar Theme Team (Orchestrating Learning). This research was supported by the Academy of Finland (Projects no. 121097 and 139538). 


\section{References}

Altheide, D.L. (1987). Ethnographic content analysis. Qualitative Sociology, 10, 65-77.

Amabile, T. M. (1983). The social psychology of creativity. New York: Springer-Verlag.

Amabile, T. M. (1997). Motivating creativity in organizations: On doing what you love and loving what you do. California Management Review, 40, 39-58.

Ambrose, D. (2005). Creativity in teaching: Essential knowledge, skills and dispositions. In J. C. Kaufman, \& J. Baer (Eds.), Creativity across domains: Faces of the muse (pp. 281-298). Hillsdale, NJ: Lawrence Erlbaum Associates.

Andiliou, A., \& Murphy, K. P. (2010). Examining variations among researchers' and teachers' conceptualizations of creativity: A review and synthesis of contemporary research. Educational Research Review, 5(3), 201-219.

Andriessen, J. (2006). Arguing to learn. In R. K. Sawyer (Ed.), Cambridge handbook of the learning sciences (pp. 443-459). New York: Cambridge University Press.

Aronson, E., Blaney, N., Stephan, C., Sikes, J., \& Snapp, M. (1978). The jigsaw classroom. Beverly Hills, CA: Sage Publications, Inc.

Arvaja, M. (2007). Contextual perspective in analysing collaborative knowledge construction of two small groups in web-based discussion. International Journal of Computer-Supported Collaborative Learning, 2(2/3), 133-158.

Arvaja, M. (2011). Analyzing the contextual nature of collaborative activity. In S. Puntambekar, G. Erkens, \& C. Hmelo-Silver (Eds.), Analyzing interactions in CSCL: Methods, approaches and issues (pp. 25-46). Computer-Supported Collaborative Learning Series, Vol. 12. New York: Springer.

Arvaja, M., Häkkinen, P., Eteläpelto, A., \& Rasku-Puttonen, H. (2000). Collaborative processes during report writing of a science learning project: The nature of discourse as a function of task requirements. European Journal of Psychology of Education, 15(4), 455-466.

Arvaja, M., Häkkinen, P., \& Kankaanranta, M. (2008). Collaborative learning and computersupported collaborative learning environments. In J. Voogt, \& G. Knezek (Eds.), International handbook of information technology in primary and secondary education (pp. 267-279). New York: Springer.

Arvaja, M., Hämäläinen, R., \& Rasku-Puttonen, H. (2009). Challenges for the teacher's role in promoting productive knowledge construction in computer-supported collaborative learning contexts. In J. O. Lindberg, \& A. D. Olofsson (Eds.), Online learning communities and teacher professional development: Methods for improved education delivery (pp. 263-280). Hersey: IGI Global.

Arvaja, M., Salovaara, H., Häkkinen, P., \& Järvelä, S. (2007). Combining individual and grouplevel perspectives for studying collaborative knowledge construction in context. Learning and Instruction, 17(4), 448-459.

Attride-Stirling J. (2001). Thematic networks: An analytic tool for qualitative research. Qualitative Research, 1(3), 385-405.

Azmitia, M. (1996). Peer interactive minds: Developmental, theoretical, and methodological issues. In P. B. Baltes, \& U. M. Staudinger (Eds.), Interactive minds: Life-span perspectives on the social foundation of cognition (pp. 133-162). New York: Cambridge.

Baker, M. (2002). Forms of cooperation in dyadic problem-solving. In P. Salembier, \& H. Benchekroun (Eds.), Cooperation and complexity (pp. 587-620). Socio-technical Systems, Vol. 16. Paris: Hermès.

Baker, M. (2003). Computer-mediated argumentative interactions for the co-elaboration of scientific notions. In J. Andriessen, M. Baker, \& D. Suthers (Eds.), Arguing to learn: Confronting cognitions in computer-supported collaborative learning environments (pp. 125). Dordrecht: Kluwer Academic Publishers. 
Baker, M. (2010, September). Approaches to understanding students' dialogues: Articulating multiple modes of interaction. Keynote speaker lecture presented to an EARLI SIG 17 'Qualitative and Quantitative Approaches to Learning and Instruction'. Jena, Germany.

Barnes, D., \& Todd, F. (1995). Communication and learning revisited: Making meaning through talk. Portsmouth: Boynton/Cook Publishers.

Barron, B. (2000). Achieving coordination in collaborative problem-solving groups. The Journal of the Learning Sciences, 9(4), 403-436.

Barron, B. (2003). When smart groups fail. The Journal of the Learning Sciences, 12(3), 307-359.

Barron, F. (1999). All creation is collaboration. In A. Montouri, \& R. Purser (Eds.), Social creativity (pp. 49-59). Cresskill: Hampton Press.

Barron, F., \& Harrington, D. (1981). Creativity, intelligence and personality. Annual Review of Psychology, 32, 439-476.

Beghetto, R. A., \& Kaufman, J. C. (2007). Toward a broader conception of creativity: A case for mini-c creativity. Psychology of the Aesthetics, Creativity and the Arts, 1(2), 73-79.

Bereiter, C. (2002). Education and mind in the knowledge age. Mahwah, NJ: Erlbaum.

Bielaczyc, K., \& Collins, A. (2006). Fostering knowledge-creating communities. In A. M. O'Donnell, C. E. Hmelo-Silver, \& G. Erkens (Eds.), Collaborative learning, reasoning, and technology (pp. 37-60). Mahwah, NJ: Lawrence Erlbaum Associates.

Billett, S. (2006). Work, change and workers. Dordrecht: Springer.

Billett, S. (2008). The workplace as learning environment: Introduction. International Journal of Educational Research, 47(4), 209-212.

Bluemink, J., Hämäläinen, R., Manninen, T., \& Järvelä, S. (2010). Group-level analysis on multiplayer-game collaboration: How do the individuals shape the group interaction? Journal of Interactive Learning Environments, 18(4), 365-383. doi:10.1080/10494820802602444

Boden, M. A. (1990). The creative mind: Myths and mechanisms. New York: Basic Books.

Braun, V., \& Clarke, V. (2006). Using thematic analysis in psychology. Qualitative Research in Psychology, 3(2), 77-101.

Brown, A. (1992). Design experiments: Theoretical and methodological challenges in creating complex interventions in classroom settings. Journal of the Learning Sciences, 2(2), 141178.

Brown, A., \& Campione, J. (1994). Guided discovery in a community of learners. In K. McGilly (Ed.), Classroom lessons: Integrating cognitive theory and classroom practice (pp. 227270). Cambridge, MA: MIT Press.

Bruffee, K. (1999). Collaborative learning: Higher education, interdependence, and the authority of knowledge. (2nd ed.). Baltimore, MD: Johns Hopkins University Press.

Chin, C. (2002). Student-generated questions: A meaningful aspect of learning in science. International Journal of Science Education, 24(5), 521-549.

Cobb, P., \& Yackel, E. (1996). Constructivist, emergent, and sociocultural perspectives in the context of developmental research. Educational Psychologist, 31, 175-190.

Cohen, E. (1994). Restructuring the classroom: Conditions for productive small groups. Review of Educational Research, 64(1), 1-35.

Collin, K., Paloniemi, S., \& Mecklin, J-P. (2010). Promoting inter-professional teamwork and learning - the case of a surgical operating theatre. Journal of Education and Work, 23(1), 43-63.

Cropley, A. J. (1997). Fostering creativity in the classroom: General principles. In M. A. Runco (Ed.), Creativity research handbook (Vol. 1) (pp. 83-114). Cresskill, NJ: Hampton Press.

Csikszentmihalyi, M. (1988). Society, culture and person: A systems view of creativity. In R. J. Sternberg (Ed.), The nature of creativity: Contemporary psychological perspectives ( $\mathrm{pp}$. 325-339). Cambridge: Cambridge University Press. 
Csikszentmihalyi, M. (1990). Flow: The psychology of optimal experience. New York: Harper \& Row.

Craft, A. (2003). Creative thinking in early years of education. Early years, 23(2), 143-154.

Craft, A. (2005). Creativity in schools: Tensions and dilemmas. London: Routledge.

Craft, A. (2008). Studying collaborative creativity: Implications for education. Thinking Skills and Creativity, 3(3), 241-245.

Craft, A., Cremin, T., Burnard, P., \& Chappell, K. (2007). Teacher stance in creative learning: A study of progression. Thinking Skills and Creativity, 2(2), 136-147.

Craft, A., Jeffrey, B., \& Leibling, M. (Eds.) (2001). Creativity in education. London: Continuum.

Crook, C. (1994). Computers and the collaborative experience of learning. London: Routledge.

Crook, C. (1998). Children as computer users: The case of collaborative learning. Computers and Education, 30, 237-247.

Davis, E. A., \& Miyake, N. (2004). Explorations of scaffolding in complex systems. The Journal of the Learning Sciences, 13(3), 265-272.

Day, C. (2002). School reform and transitions in teacher professionalism and identity. International Journal of Educational Research, 37(8), 677-692.

De Corte, E. (1996). Toward the integration of computers in powerful learning environments. In S. Vosniadou, E. DeCorte, \& H. Mandl (Eds.), Technology-Based Learning Environments. Psychological and Educational Foundations (pp. 79-85). New York: Springer.

De Dreu, C. K. W., \& West, M. A. (2001). Minority dissent and team innovation: The importance of participation in decision making. Journal of Applied Psychology, 8(6), 1191-1201.

De Laat, M., \& Lally, V. (2004). It's not so easy: Researching the complexity of emergent participant roles and awareness in asynchronous networked learning discussions. Journal of Computer Assisted Learning, 20(3), 165-171.

De Wever, B., Schellens, T., Valcke, M., \& Van Keer, H. (2006). Content analysis schemes to analyze transcripts of online asynchronous discussion groups: A review. Computers \& Education, 46(1), 6-28.

De Wever, B., Van Keer, H., Schellens, T., \& Valcke, M. (2010). Structuring asynchronous discussion groups: Comparing scripting by assigning roles with regulation by cross-age peer tutors. Learning and Instruction, 20(5), 349-360.

Dillenbourg, P. (1999). What do you mean by 'collaborative learning'? In P. Dillenbourg (Ed.), Collaborative learning: Cognitive and computational approaches (pp. 1-16). Amsterdam: Pergamon, Elsevier Science.

Dillenbourg, P. (2002). Over-scripting CSCL: The risks of blending collaborative learning with instructional design. In P. A. Kirschner (Ed.), Three worlds of CSCL. Can we support CSCL? (pp. 61-91). Heerlen: Open Universiteit Nederland.

Dillenbourg, P. (2006). The solo/duo gap. Computers in Human Behavior, 22(1), 155-159.

Dillenbourg P., Järvelä S., \& Fischer F. (2009). The evolution of research on computer-supported collaborative learning: From design to orchestration. In Balacheff, N., Ludvigsen, S., de Jong, T., Lazonder, T. A., \& Barnes, S. (Eds.), Technology enhanced learning: Principles and products (pp. 3-19). Netherlands: Springer.

Dillenbourg, P., \& Jermann, P. (2007). Designing integrative scripts. In F. Fischer, H. Mandl, J. Haake, \& I. Kollar (Eds.), Scripting computer-supported collaborative learning: Cognitive, computational and educational perspectives (pp. 275-301). New York: Springer.

Dillenbourg, P., \& Jermann, P. (2010). Technology for classroom orchestration. In M. S. Khine, \& I. M. Saleh (Eds.), New science of learning (pp. 525-552). New York: Springer Science+Business Media.

Dillenbourg, P., \& Tchounikine, P. (2007). Flexibility in macro-scripts for computer-supported collaborative learning. Journal of Computer Assisted Learning, 23(1), 1-13. 
Doise, W., \& Mugny, G. (1986). Individual and collective conflicts of centrations in cognitive development. European Journal of Social Psychology, 9, 105-108.

Eteläpelto, A., \& Lahti, J. (2008). The resources and obstacles of creative collaboration in longterm learning community. Thinking Skills and Creativity, 3(3), 226-240.

Faulkner, D., Joiner, R., Littleton, K., Miell, D., \& Thompson, L. (2000). The mediating effect of task presentation on collaboration and children's acquisition of scientific reasoning. European Journal of Psychology of Education, 15(4), 418-431.

Feldhusen, J. F., \& Hobson, S. K. (1972). Freedom and play: Catalysts for creativity. Elementary School Journal, 73, 149-155.

Fischer, F., \& Dillenbourg, P. (2006, April). Challenges of orchestrating computer-supported collaborative learning. Paper presented at the 87th Annual Meeting of the American Educational Research Association (AERA), San Francisco, CA.

Fleith, D. S. (2000). Teacher and student perceptions of creativity in the classroom environment. Roeper Review, 22(3), 148-157.

Florida, R. (2002). The rise of the creative class and how it's transforming work, life, community and everyday life. New York: BasicBooks.

Gall, M., \& Breeze, N. (2008). Music and eJay: An opportunity for creative collaborations in the classroom. International Journal of Educational Research, 47(1), 27-40.

Gee, J. P., \& Green, J. L. (1998). Discourse analysis, learning, and social practice: A methodological study. Review of Educational Research, 23, 119-169.

Glăveanu, V. P. (2010). Paradigms in the study of creativity: Introducing the perspective of cultural psychology. New Ideas in Psychology, 28(1), 79-93.

Grossen, M. (2008). Methods for studying collaborative creativity: An original and adventurous blend. Thinking Skills and Creativity, 3(3), 246-249. doi:10.1016/j.tsc.2008.09.005.

Guilford, J. P. (1950). Creativity. The American Psychologist, 5(9), 444-454.

Hämäläinen, R. (2008). Designing and evaluating collaboration in a virtual game environment for vocational learning. Computers \& Education, 50(1), (98-109).

Hämäläinen, R. (2011). Using a game environment to foster collaborative learning: a designbased study. Technology, Pedagogy and Education, 20(1), (45-62).

Hämäläinen, R., \& Arvaja, M. (2009). Scripted collaboration and group-based variations in a higher education CSCL context. Scandinavian Journal of Educational Research, 53(1), 116.

Hämäläinen, R., \& Häkkinen, P. (2010). Teachers' instructional planning for computer-supported collaborative learning: Macro-scripts as a pedagogical method to facilitate collaborative learning. Teaching and Teacher Education, 26(4), 871-877.

Hämäläinen, R., Oksanen, K., \& Häkkinen, P. (2008). Designing and analyzing collaboration in a scripted game for vocational education. Computers in Human Behavior, 24(6), 2496-2506.

Hamilton, R. J. (1997). Effects of three types of elaboration on learning concepts from text. Contemporary Educational Psychology, 22(3), 299-318.

Hargreaves, A. (2000). Four ages of professionalism and professional learning. Teachers and Teaching: Theory and Practice, 6(2), 151-182.

Hewitt, A. (2008). Children's creative collaboration during a computer-based music task. International Journal of Education, 47, 11-26. doi:10.1016/j.jjer.2007.11.003.

Hmelo-Silver, C. E., \& Barrows, H. S. (2008). Facilitating collaborative knowledge building. Cognition and Instruction, 26, 48-94.

Hodkinson, P., \& Hodkinson, H. (2003). Individuals, communities of practice and the policy context: School teachers' learning in their workplace. Studies in Continuing Education, 25(1), 3-21.

Hökkä, P., Rasku-Puttonen, H., \& Eteläpelto, A. (2008). Teacher educators' workplace learning. The interdependency between individual agency and social context. In S. Billett, C. Harteis, 
\& A. Eteläpelto (Eds.), Emerging perspectives of workplace learning (pp. 51-65). Rotterdam: Sense.

Järvenoja, H., \& Järvelä, S. (2009). Emotion control in collaborative learning situations - Do students regulate emotions evoked from social challenges? British Journal of Educational Psychology, 79(3), 463-481.

Jeong, H., \& Hmelo-Silver, C. E. (2010). Productive use of learning resources in an online problem-based learning environment. Computers in Human Behavior, 26(1), 84-99.

John-Steiner, V. (2000). Creative collaboration. Oxford: Oxford University Press.

Jordan, B., \& Henderson, A. (1995). Interaction analysis: Foundations and practice. Journal of the Learning Sciences, 4, 39-103.

Kampylis, P., Berki, E., \& Saariluoma, P. (2009). In-service and prospective teachers' conceptions of creativity. Thinking Skills and Creativity, 4(1), 15-29.

Kelly, G., Crawford, T., \& Green, J. (2001). Common task and uncommon knowledge: Dissenting voices in the discursive construction of physics across small laboratory groups. Linguistics \& Education, 12(2), 135-174.

Kirpal, S. (2004). Researching work identities in a European context. Career Development International, 9(3), 199-221.

Kneser, C., \& Ploetzner, R. (2001). Collaboration on the basis of complementary domain knowledge: Observed dialogue structures and their relation to learning success. Learning and Instruction, 11, 53-83.

Kobbe, L., Weinberger, A., Dillenbourg, P., Harrer, A., Hämäläinen, R., \& Häkkinen, P. (2007). Specifying computer-supported collaboration scripts. International Journal of ComputerSupported Collaborative Learning, 2(2/3), 211-224.

Kollar, I. (2010). Turning the classroom of the future into the classroom of the present. In K. Mäkitalo-Siegl, J. Zottmann, F. Kaplan, \& F. Fischer (Eds.), The classroom of the future: Orchestrating collaborative learning spaces (pp. 245-255). Rotterdam: Sense.

Kollar, I., Fischer, F., \& Hesse, F. W. (2006). Collaboration scripts: A conceptual analysis. Educational Psychology Review, 18, 159-185.

Kollar, I., Fischer, F., \& Slotta, J. (2008). Internal and external scripts in computer-supported collaborative inquiry learning. Learning \& Instruction, 17(6), 708-721.

Kollar, I., Hämäläinen, R., Evans, M., De Wever, B., \& Perrotta, C. (2011). Orchestrating CSCL More than a metaphor? CSCL 2011 conference, Hong Kong, China.

Koschmann, T. (1996). CSCL: Theory and practice of an emerging paradigm. Mahwah, NJ: LEA.

Krange, I., \& Ludvigsen, S. (2008). What does it mean? Students' procedural and conceptual problem solving in a CSCL environment designed within the field of science education. International Journal of Computer-Supported Collaborative Learning (ijCSCL), 3(1), 25-52.

Kumpulainen, K., \& Mutanen, M. (2000). Mapping the dynamics of peer group interaction: A method of analysis of socially shared learning processes. In H. Cowie, \& G. v. d. Aalsvoort (Eds.), Social interaction in learning and instruction: The meaning of discourse for the construction of knowledge (pp. 144-160). New York: Elsevier Science.

Lahti, J., Eteläpelto, A., \& Siitari, S. (2004). Conflict as a challenge to productive learning during long-term collaboration. In K. Littleton., D. Miell, \& D. Faulkner (Eds.), Learning to collaborate: Collaborating to learn (pp. 145-160). New York: Nova Science Publishers.

Lasky, S. (2005). A sociocultural approach to understanding teacher identity, agency and professional vulnerability in a context of secondary school reform. Teaching and Teacher Education, 21(8), 899-916.

Laurillard, D. (2009). The pedagogical challenges to collaborative technologies. International Journal of Computer-Supported Collaborative Learning, 4(1) 5-20. 
Lazonder, A. W., Wilhelm, P., \& Ootes, S. A. W. (2003). Using sentence openers to foster student interaction in computer-mediated learning environments. Computers \& Education, 41, 291308.

Leitão, S. (2000). The potential of argument in knowledge building. Human Development, 43(6), 332-360.

Littleton, K., \& Häkkinen, P. (1999). Learning together: Understanding the processes of computerbased collaborative learning. In P. Dillenbourg (Ed.), Collaborative learning: Cognitive and computational approaches (pp. 20-31). Oxford: Pergamon.

Littleton, K., \& Whitelock, D. (2005). The negotiation and co-construction of meaning and understanding within a postgraduate online learning community. Learning, Media and Technology, 30(2), 147-164.

MacDonald, R., \& Miell, D. (2000). Creativity and music education: The impact of social variables. International Journal of Music Education, 36, 58-68.

Marttunen, M., Laurinen, L., Litosseliti, L., \& Lund, K. (2005). Argumentation skills as prerequisites for collaborative learning among Finnish, French and English secondary school students. Educational Research and Evaluation, 11(4), 365-384.

Mercer, N. (1996). The quality of talk in children's collaborative activity in classroom. Learning and Instruction, 6(4), 359-377.

Mercer, N. (2010). The analysis of classroom talk: Methods and methodologies. The British Journal of Educational Psychology, 80, 1-14.

Mercer, N., Dawes, L., Wegerif, R., \& Sams, C. (2004). Reasoning as scientist: Ways of helping children to use language to learn science. British Educational Research Journal, 30(3), 359-377.

Mercer, N., Hennessy, S., \& Warwick, P. (2010). Using interactive whiteboards to orchestrate classroom dialogue, Technology, Pedagogy and Education, 19(2), 195-209.

Mercer, N., \& Littleton, K. (2007). Dialogue and the development of children's thinking. A sociocultural approach. London: Routledge.

Meyer, H.-D. (2002). From 'loose coupling' to 'tight management'? Making sense of the changing landscape in management and organization theory. Journal of Educational Administration, 40(6), 515-520.

Miell, D., \& Littleton, K. (2004). Collaborative creativity: Contemporary perspectives. London: Free Association Books.

Miell, D., \& Littleton, K. (2008). Musical collaboration outside school: Processes of negotiation in band rehearsals. International Journal of Educational Research, 47(1), 41-49.

Moran, S. (2010). Creativity in school. In K. Littleton, C. Woods, \& J. K. Staarman (Eds.) International handbook of psychology in education (pp. 319-359). Bingley, UK: Emerald Group Publishing Limited.

Moran S., \& John-Steiner, V. (2003). Creativity in the making. In R. K. Sawyer, V. John-Steiner, S. Moran, R. Sternberg, D.H. Feldman, M. Csikszentmihalyi, \& J. Nakamura (Eds.), Creativity and development (pp. 61-90). Oxford: Oxford University Press.

Moran, S., \& John-Steiner, V. (2004). How collaboration in creative work impacts identity and motivation. In D. Miell, \& K. Littleton (Eds.), Collaborative creativity: Contemporary perspectives (pp. 11-25). London: Free Association Books.

Newman, D., Griffin, P., \& Cole, M. (1989). The construction zone: Working for cognitive change in schools. Cambridge: Cambridge University Press.

Nijstad, B. A., \& Paulus, P. B. (2003). Group creativity: Common themes and future direction. In P. B. Paulus, \& B. A. Nijstad (Eds.), Group creativity: Innovation through collaboration (pp. 326-339). New York: University Press.

Palincsar, A., \& Brown, A. (1984). Reciprocal teaching of comprehension-fostering and comprehension-monitoring activities. Cognition and Instruction, 1(2), 117-175. 
Paulus, P. B., \& Nijstad, B. A. (2003). Group creativity: Innovation through collaboration. New York: University Press.

Pea, R. D. (1993). Practices of distributed intelligence and designs for education. In G. Salomon (Ed.), Distributed cognitions. Psychological and educational considerations (pp. 47-87). Cambridge: Cambridge University Press.

Pea, R. D. (1994). Seeing what we build together: Distributed multimedia learning environments for transformative communications. Journal of the Learning Sciences, 3(3), 285-299.

Pea, R. D. (2004). The social and technological dimensions of scaffolding and related theoretical concepts for learning, education, and human activity. Journal of the Learning Sciences, 13(3), 423-451.

Piaget, J. (1926). The child's conception of the world. London: Routledge and Kegan Paul.

Piaget, J. (1980). Adaptation and intelligence. London: University of Chicago Press.

Piaget, J. (1985). Equilibration of cognitive structures. University of Chicago Press.

Piirto, J. (2004). Understanding creativity (Revised edition of Understanding those who create, 2nd ed., 1998). Scottsdale, AZ: Great Potential Press.

Puntambekar, S., \& Young, M. F. (2003). Moving toward a theory of CSCL. In U. Hoppe, B. Wasson, \& S. Ludvigson (Eds.), Computer supported collaborative learning 2003: Designing for change in networked learning (pp. 503-512). Amsterdam: IOS Press.

Qin, Z., Johnson, D. W., \& Johnson, R. T. (1995). Cooperative versus competitive efforts and problem solving. Review of Educational Research, 65(2), 129-143.

Reiser, B. J. (2004). Scaffolding complex learning: The mechanisms of structuring and problematizing student work. Journal of the Learning Sciences, 13(3), 273-304.

Rejskind, G. (2000). TAG teachers: Only the creative need apply. Roeper Review, 22(3), 153157.

Resnick, L. B., Salmon, M., Zeitz, C. M., Wathen, S. H., \& Holowchak, M. (1993). Reasoning in conversation. Cognition and Instruction, 11(3\&4), 347-364.

Reusser, K. (2001). Co-constructivism in educational theory and practice. In N. J. Smelser, P. Baltes, \& F. E. Weinert (Eds.), International encyclopaedia of social and behavioural sciences (pp. 2058-2062). Oxford: Pergamon/Elsevier Science.

Rojas-Drummond, S., Mazon, N., Fernandez, M., \& Wegerif, R. (2006). Explicit reasoning, creativity and co-construction in primary school children's collaborative activities. Thinking Skills and Creativity, 1(2), 84-94.

Roschelle, J. (1992). Learning by collaborating: Convergent conceptual change. Journal of the Learning Sciences, 2(3), 235-276.

Roschelle, J., \& Teasley, S. (1995). The construction of shared knowledge in collaborative problem solving. In C. O'Malley (Ed.), Computer supported collaborative learning (pp. 6997). NATO ASO Series F: Computer and System Sciences, Vol. 128. Berlin: SpringerVerlag.

Ruiz-Primo, M. A., Briggs, D., Iverson, H., Talbot, R., \& Shepard, L. A. (2011). Impact of undergraduate science course innovations on learning. Science, 331, 1269-1270.

Ruiz-Primo, M. A., Figueroa, M., \& Gluckman, M. (2011). Testing a premise of inquiry based science instruction: Exploring small group processes and its link to student learning. Paper presented at the AERA meeting, April 2011.

Sandoval, W. (2003). Conceptual and epistemic aspects of students' scientific explanations. Journal of the Learning Sciences, 12(1), 5-51.

Sandoval, W. A., \& Reiser, B. J. (2004). Explanation-driven inquiry: Integrating conceptual and epistemic scaffolds for scientific inquiry. Science Education, 88, 345-372.

Sarmiento, J., \& Stahl, G. (2008). Group creativity in inter-action: Referencing, remembering and bridging. International Journal of Human-Computer Interaction (IJHCl), 24(6), 492-504.

Sawyer, R. K. (2003). Group creativity: Music, theater, collaboration. Mahwah, NJ: Erlbaum. 
Sawyer, R. K. (2004). Creative Teaching: Collaborative discussion as disciplined improvisation. Educational Researcher, 33(3), 12-20.

Sawyer, R. K. (2006a). Educating for innovation. Thinking Skills and Creativity, 1(1), 41-48.

Sawyer, R. K. (2006b). Explaining creativity: The science of human innovation. New York: Oxford University Press.

Sawyer, R. K. (2007). Group genius: The creative power of collaboration. New York: BasicBooks.

Sawyer, R. K., \& Berson, S. (2004). Study group discourse: How external representations affect collaborative conversation. Linguistics and Education, 15, 387-412.

Sawyer, R. K., \& DeZutter, S. (2009). Distributed creativity: How collective creations emerge from collaboration. Journal of Aesthetics, Creativity, and the Arts, 3(2), 81-92.

Scardamalia, M., \& Bereiter, C. (1991). Higher levels of agency for children in knowledge building: A challenge for the design of new knowledge media. The Journal of the Learning Sciences, 1, 37-68.

Scardamalia, M., \& Bereiter, C. (1994). Computer support for knowledge-building communities. The Journal of the Learning Sciences, 3(3), 265-283.

Scardamalia, M., \& Bereiter, C. (2006). Knowledge building. In R. K. Sawyer (Ed.), Cambridge handbook of the learning sciences (pp. 97-115). New York: Cambridge University Press.

Schellens, T., Van Keer, H., De Wever, B., \& Valcke, M. (2007). Scripting by assigning roles: Does it improve knowledge construction in asynchronous discussion groups? International Journal of Computer-Supported Collaborative Learning, 2(2/3), 225-246.

Shalley, C. E., \& Gilson, L. L. (2004). What leaders need to know: A review of social and contextual factors that can foster or hinder creativity. The Leadership Quarterly, 15(1), 3353.

Silva, E. (2008). Measuring skills for the 21st century. Washington, DC: Education Sector. Retrieved January 18, 2011 from http://www.educationsector.org/research/research_show.htm?doc_id=716323

Springer, L., Stanne, M. E., \& Donovan, S. S. (1999). Effects of small-group learning on undergraduate in science, mathematics, engineering, and technology: A meta-analysis. Review of Educational Research, 69(1), 21-51.

Stahl, G. (2003). Communication and learning in online collaboration. Paper presented at GROUP_03, Sannibel Island, Florida. Retrieved November 9, 2010, from http://www.cis.drexel.edu/faculty/gerry/publications/conferences/2003/group/group03.doc

Stahl, G. (2004). Building collaborative knowing. Elements of a social theory of CSCL. In P. Dillenbourg (Series Ed.) \& J. W. Strijbos, P. A. Kirschner, \& R. L. Martens (Eds.), Computer-supported collaborative learning, Vol. 3: What we know about CSCL... and implementing it in higher education (pp. 53-85). Boston, MA: Kluwer Academic Publishers.

Stahl, G. (2006). Group cognition: Computer support for building collaborative knowledge. Cambridge, MA: MIT Press. Retrieved 29.6.2011. http://www.cis.drexel.edu/faculty/gerry/mit/

Stahl, G., Koschmann, T., \& Suthers, D. (2006). Computer-supported collaborative learning: A historical perspective. In R. K. Sawyer (Ed.), Cambridge handbook of the learning sciences (pp. 406-427). Cambridge: Cambridge University Press. Retrieved May 30, 2011 from http://www.cis.drexel.edu/faculty/gerry/cscl/CSCL_English.pdf

Stegmann, K., Weinberger, A., \& Fischer, F. (2007). Facilitating argumentative knowledge construction with computer-supported collaboration scripts. International Journal of Computer-Supported Collaborative Learning, 2(4), 421-447.

Sternberg, R. J., \& Lubart, T. I. (1999). The concept of creativity: Prospects and paradigms. In R. J. Sternberg (Ed.), Handbook of creativity (pp. 3-15). Cambridge: Cambridge University Press. 
Sternberg, R. J., \& Williams, W. M. (1996). How to develop student creativity. Alexandria, VA: Association for Supervision and Curriculum Development.

Stone, C. A. (1993). What is missing in the metaphor of scaffolding? In E. A. Forman, N. Minick, \& C. A. Stone (Eds.), Contexts for learning: Sociocultural dynamics in children's development (pp. 169-183). New York: Oxford University Press.

Strijbos, J. W., \& De Laat, M. F. (2010). Developing the role concept for computer-supported collaborative learning: An explorative synthesis. Computers in Human Behavior, 26, 495505.

Suthers, D. (2005). Technology affordances for intersubjective learning: A thematic agenda for CSCL. In T. Koschmann, D. Suthers, \& T.W. Chan (Eds.), Proceedings of computer supported collaborative learning 2005: The next 10 years! (pp. 662-671). Mahwah, NJ: Lawrence Erlbaum Associates

Tardif, T., \& Sternberg, R. (1988). What do we know about creativity? In R. J. Sternberg (Ed.), The nature of creativity: Contemporary psychological perspectives (pp. 429-440). Cambridge: Cambridge University Press.

Torrance, E. P. (1965). Rewarding creative behavior: Experiments in classroom creativity. Englewood Cliffs, NJ: Prentice-Hall

Troman, G., Jeffrey, B., \& Raggl, A. (2007). Creativity and performativity policies in primary school cultures. Journal of Education Policy, 22(5), 549-572.

Vähäsantanen, K. (2009). Learning about professional self among vocational teachers. Paper presented at the 6th International Conference on Researching Work and Learning (RWL), June 28-July 1, Roskilde, Denmark.

Vähäsantanen, K., \& Billett, S. (2008). Negotiating professional identity: Vocational teachers' personal strategies in a reform context. In S. Billett, C. Harteis, \& A. Eteläpelto (Eds.), Emerging perspectives of workplace learning (pp. 35-49). Rotterdam: Sense.

Vähäsantanen, K. \& Eteläpelto, A. (2011, submitted). Agency within career pathway transitions: Subjects' disengagement from the work organisation. Studies in Continuing Education.

Vähäsantanen, K., Hökkä, P., Eteläpelto, A., Rasku-Puttonen, H., \& Littleton, K. (2008). Teachers' professional identity negotiations in two different work organisations. Vocations and Learning: Studies in Vocational and Professional Education, 1(2), 131-148.

Valleala, U., Arvaja, M., \& Hämäläinen, R. (2010). Towards research based online collaborative learning. In L. Chova, D. Belenguer, \& I. Torres (Eds.), Proceedings of EDULEARN 10 Conference, July 5-7, Barcelona, Spain, (pp. 5276-5285) Valencia, Spain: International Association of Technology, Education and Development (IATED).

Van Boxtel, C., Van der Linden, J., \& Kanselaar, G. (2000). Collaborative learning tasks and the elaboration of conceptual knowledge. Learning and Instruction, 10(4), 311-330.

Vass, E., \& Littleton, K. (2009). Analysing role distribution in children's computer-mediated collaborative creative writing. In K. Kumpulainen, C. E. Hmelo-Silver, \& M. César (Eds.), Investigating classroom interaction: Methodologies in action (pp. 99-120).Rotterdam: Sense.

Voogt, J. (2008). IT and curriculum processes: dilemmas and challenges. In J. Voogt, \& G. Knezek (Eds.), International handbook of information technology (pp. 117-132). New York: Springer.

Vygotsky, L. (1978). Mind and society. Cambridge, MA: Harvard University Press.

Webb, N. (1984). Sex differences in interaction and achievement in cooperative small groups. Journal of Educational Psychology, 76(1), 33-44.

Webb, N. (1989). Peer interaction and learning in small groups. International Journal of Educational Research, 13(1), 21-39. 
Webb, N., \& Palincsar, A. (1996). Group processes in the classroom. In D. Berliner, \& R. Calfee (Eds.), Handbook of educational psychology (pp. 841-873). New York: Simon \& Schuster Macmillan.

Webb, N. M., Ender, P., \& Lewis, S. (1986). Problem-solving strategies and group processes in small groups learning computer programming. American Educational Research Journal, 23(2), 243-261.

Wegerif, R. (2005). Reason and creativity in classroom dialogues. Language and Education, 19(3), 223-238.

Weinberger, A., Ertl, B., Fischer, F., \& Mandl, H. (2005). Epistemic and social scripts in computersupported collaborative learning. Instructional Science, 33(1), 1-30.

Wells, G., \& Arauz, R. M. (2006). Dialogue in the classroom. Journal of the Learning Sciences, 15(3), 379-428.

Wells, G. \& Claxton, G. (2002). Introduction: Sociocultural perspectives on the future of education. In G. Wells, \& G. Claxton (Eds.), Learning for life in the 21st century: Sociocultural perspectives on the future of education (pp. 1-18). Oxford: Blackwell.

Wertsch, J., Tulviste, P., \& Hagstrom, F. (1993). A sociocultural approach to agency. In. A. Forman, N. Minick, \& A. Stone (Eds.), Contexts for learning sociocultural dynamics in children's development (pp. 336-357). New York: Oxford University Press.

Wertsch, J. V. (1998). Mind as action. New York: Oxford.

West, M. A. (2003). Innovation implementation in work teams. In P. B. Paulus, \& B. A. Nijstad (Eds.), Group creativity: Innovation through collaboration (pp. 245-276). New York: University Press.

Wood, D., Bruner, J. S., \& Ross, G. (1976). The role of tutoring in problem solving. Journal of Child Psychology and Psychiatry, 17, 89-100.

Woods, P. (2002). Teaching and learning in the new millennium. In C. Surgue, \& C. Day (Eds.), Developing teachers and teaching practice: International research perspectives (pp. 73-91). London: Routledge.

Zhang, J., Scardamalia, M., Reeve, R., \& Messina, R. (2009). Designs for collective cognitive responsibility in knowledge building communities. Journal of the Learning Sciences, 18(1), $7-44$. 